\title{
El estudio de nuestro microcosmos: las comunidades microbianas asociadas al cuerpo humano
}

\author{
(The study of our microcosm: the microbial community related to the human body)
}

\author{
Jenny Llanos Villarreal \\ Escuela de Medicina - Universidad de Valparaíso \\ E- mail: jenny.llanos@uv.cl
}

Palabras claves: microbioma, salud, enfermedad

Key words: microbiome, health, disease

RECIBIDO: 23-12-13

APROBADO: $30-12-13$

\section{RESUMEN}

El cuerpo humano presenta una gran variedad de micro nichos que están colonizados por diversos grupos de microorganismos, principalmente bacterias, que establecen con nuestro cuerpo una relación simbionte y colaboran de manera positiva a nuestra biología. En los últimos años, diversos grupos multinacionales han emprendido la tarea de estudiar, mediante avanzados procedimientos de análisis molecular y bioinformáticos, las comunidades microbianas que habitan nuestro cuerpo. Este artículo, pretende entregar una visión global de cómo, en la actualidad, se está abordando el estudio de nuestro microcosmos y cuáles son los aspectos más sobresalientes derivados de los mismos.

\section{INTRODUCCIÓN}

A finales de la primera década del siglo XXI, el conocimiento respecto de las especies que componen las comunidades microbianas asociadas al hombre se ha incrementado en forma vertiginosa, prueba de ello, es el creciente número de publicaciones que abordan este tema. De acuerdo a antecedentes obtenidos desde la base de datos de PubMed, al consultar por «Human Microbiome», obtenemos que entre el 2000 y el 2003 fueron publicados en total 15 trabajos en torno a este tema, aumentando progresivamente en los tres años siguientes, llegando a 50 publicaciones en el 2007. A partir de esta fecha la cifra se ha ido duplicando año a año, teniendo 122, $219,520,825$ y 1.417 en el 2008, 2009, 2010, 2011 y 2012 respectivamente.

\section{ABSTRACT}

The human body has great variety of micro niches that are colonized by various groups of microorganisms, mainly bacteria, which provide our body with a symbiotic relationship and collaborate in a positive way to our biology. In recent years, various multinational groups have undertaken the task of studying, using advanced methods of molecular and bioinformatic analysis, microbial communities inhabiting our bodies. This article aims to give an overview of how, at present, is being addressed the study of our microcosm and what aspects are most over projections derived from them.

Este aumento exponencial, se debe en gran medida al esfuerzo colectivo de grupos de investigación multinacionales, que han abordado el estudio de la microbiota asociada al hombre, mediante procedimientos de análisis molecular y bioinformático. Este artículo tiene por finalidad entregar una visión global respecto de cómo, al día de hoy, se está abordando el estudio de los microorganismos simbiontes que colonizan nuestro cuerpo.

\section{El cuerpo humano: un gran ecosistema para los microorganismos}

El cuerpo humano posee una diversidad de ambientes (micro nichos), que pueden ser colonizados por diversos grupos de microorganismos, principalmente bacterias. Esta variedad de comunidades microbianas, que establecen con 
El estudio de nuestro microcosmos: las comunidades microbianas asociadas al cuerpo humano - J. Llanos.

nuestro cuerpo una relación simbionte de comensalismo y mutualismo, recibe colectivamente el nombre de microbioma (o microbiota). La relación entre las células que componen nuestro microbioma y las células que forman nuestro cuerpo es de 10:1, es decir que ipor cada célula de nuestro cuerpo, contamos con 10 células microbianas! [3, 23].

Al considerar los billones de bacterias y otros microorganismos que habitan superficies y cavidades de nuestro cuerpo, principalmente piel, boca, nariz, zona genital e intestinos; se debe tomar en cuenta los millones de genes microbianos, cuya expresión nos permite llevar a cabo funciones metabólicas, no codificadas por el genoma humano. El conjunto de genes microbianos, constituye el metagenoma humano y su número excede largamente el de nuestros propios genes [16]. Desde una óptica moderna, podemos entender nuestra dotación genética como un agregado de nuestro genoma más el metagenoma y por ello, se estima que el estudio del metagenoma humano ayudará a identificar los beneficios que nos aportan los distintos microorganismos.

Es tal la relevancia de este aspecto, que ciertos autores han señalado que el cuerpo humano puede ser considerado como un supra-organismo, formado por un componente humano y otro microbiano y, por lo tanto, para comprender la diversidad genética y fisiológica de nuestro organismo, se debe caracterizar nuestro microbioma y los factores que afectan su distribución y evolución [23].

Costello et al. [3], señalan que el conocer la «biogeografía» de las comunidades bacterianas que habitan el cuerpo humano, es clave para establecer las bases de lo que consideramos sano, para así poder detectar diferencias asociadas con enfermedad.

\section{Aunando esfuerzos para comprender el rol de las comunidades microbianas asociadas al hombre}

Los microorganismos que habitan nuestro cuerpo, han generado el interés de microbiólogos desde hace mucho tiempo, pero a pesar de ello, durante el siglo pasado su estudio no tuvo un desarrollo significativo, debido a la dificultad de estudiar estos microorganismos en su ambiente natural, es decir, nuestro cuerpo; y también a la dificultad de reproducir in vitro las condiciones físicoquímicas particulares, en su gran mayoría desco- nocidas, de cada zona específica de nuestro cuerpo. Debido a esto, los numerosos y muy diversos componentes de la microbiota, son mayoritariamente no cultivables o muy difíciles de desarrollar en el laboratorio. Sin embargo, actualmente gracias a los modernos procedimientos de secuenciación de genes, los investigadores pueden procesar miles de pares de bases en pocas horas sin hacer uso de cultivos microbianos. De esto modo, se pueden identificar los microorganismos presentes en un ecosistema, sus genes e incluso los genes que los organismos viables están expresando en un momento dado (transcriptoma). Este tipo de análisis ha posibilitado la caracterización de complejas comunidades microbianas como por ejemplo nuestra microbiota, generándose información útil sobre los genes microbianos implicados en la producción de aminoácidos, degradación de variedad de compuestos y otros aspectos asociados al metabolismo humano [15].

Lo anteriormente expuesto, ha significado un fuerte impulso al estudio de nuestro microbioma, como lo demuestran los diversos proyectos que, en los últimos años, se han generado en torno a este tema (Tabla 1) y cuyos objetivos fundamentales convergen en la siguiente idea: caracterizar mediante procedimientos de secuenciación masiva, nuestra microbiota y estudiar cómo los cambios en su composición y diversidad se asocian con la salud y enfermedad. Los proyectos Microbioma humano y MetaHit destacan por el presupuesto y los grupos de trabajo involucrados en su desarrollo.

\section{Proyecto microbioma humano}

En el año 2008, el National Institutes of Health (Estados Unidos), dio inició al proyecto microbioma humano (HMP: Human Microbiome Project) [7], con el fin de:

- Desarrollar un marco de referencia para las secuencias del genoma microbiano y llevar a cabo una caracterización preliminar del microbioma - Investigar la relación entre enfermedad y los cambios en el microbioma humano - Desarrollar nuevas metodologías y herramientas computacionales de análisis

- Estudiar las implicancias éticas, legales y sociales con conlleva el estudio del microbioma humano -Establecer un «depósito» para los materiales generados por el HMP (organismos cultivados y su ADN, muestras de ADN metagenómico, etc.) 
El estudio de nuestro microcosmos: las comunidades microbianas asociadas al cuerpo humano - J. Llanos.

Tabla 1: Proyectos que aborda el estudio del microbioma humano

\begin{tabular}{|c|c|c|c|}
\hline Proyectos y Sitio Web & Paises & Duración & Presupuesto \\
\hline $\begin{array}{l}\text { Human Microbiome Project } \\
\text { (http://www.hmpdacc.org/) }\end{array}$ & Estados Unidos & 2008-2009 & U\$115 millones \\
\hline $\begin{array}{l}\text { MicroObes } \\
\text { (http://wwwinra.fr/micro_obes_eng//2 }\end{array}$ & Francia & 2008-2010 & u\$3 millones \\
\hline $\begin{array}{l}\text { MetaHit } \\
\text { (http://www.metahit.eu/) }\end{array}$ & Unión Europea y China & $2008-2011$ & U\$31 millones \\
\hline $\begin{array}{l}\text { Canadian Human Microbiome Initiative } \\
\text { (http://www.cihr-irsc.gc.ca/e/39951.html) }\end{array}$ & Canadá & 2009 & U\$10 millones \\
\hline Human MetaGenome Consortium & Japón & - & u\$5 millones \\
\hline Meta-GUT & China & - & U\$1,5 millones \\
\hline Human Gastric Microbiome & Singapur & - & U\$750.000 \\
\hline Australian Urogenital Microbiome Consortium & Australia & - & $U \$ 600.000$ \\
\hline $\begin{array}{l}\text { Microbiome Diversity Using Korean Twin } \\
\text { Cohort }\end{array}$ & Corea & $2010-2015$ & U\$2 millones \\
\hline $\begin{array}{l}\text { International Human Microbiome Standards } \\
\text { (http://www.microbiome-standards.org/) }\end{array}$ & $\begin{array}{l}\text { España, Francia, EEUU, } \\
\text { China }\end{array}$ & 2011-2015 & 2 millones $€$ \\
\hline MetaGenoPolis (www.mgps.eu) & Francia & 2012-2019 & 19 millones $€$ \\
\hline
\end{tabular}

Fuente de datos: $h t t p: / / w w w . h u m a n-m i c r o b i o m e . o r g / i n d e x . p h p ? i d=30$ y citas $[15,9]$.

provenientes de diversas zonas del cuerpo humano: nariz, cavidad bucal, piel, tracto gastrointestinal y urogenital.

\section{Proyecto MetaHit}

El Proyecto MetaHit, en español «Metagenómica del tracto intestinal humano», iniciado también en el año 2008 y financiado por la Comisión Europea, está constituido por representantes de entidades académicas y privadas que suman en total 8 países. El proyecto aborda principalmente al análisis de la microbiota intestinal y su relación con obesidad y la enfermedad inflamatoria de Bowel. Mullard [15], remarca que: «mientras el proyecto microbioma humano compara la microbiota de los individuos a nivel de especie, el objetivo de MetaHit es identificar diferencias en los genes microbianos y las proteínas que ellos expresan, sin identificar necesariamente las especies que las producen».

\section{Consorcio Internacional Microbioma Humano}

Los diversos proyectos abocados al estudio del microbioma humano, están generando una gran cantidad de información y los investigadores que
DNA y forma de consignar Ios datos. Así, diversas reuniones internacionales se han llevado a cabo desde el 2005, para discutir la formación de un Consorcio Internacional del Microbioma Humano (IHMC), con el fin de coordinar las iniciativas microbioma de todo el mundo.

\section{El Ianzamiento oficial del Consorcio} Internacional Microbioma Humano (IHMC), se produjo en el 2008 en Heidelber (Alemania). En esta oportunidad representantes del Instituto Nacional de Salud (NIH, Estados Unidos) y la Comisión Europea (CE), acordaron cooperar en sus esfuerzos para liberar los datos de los Proyectos «Microbioma Humano» y «Metagenómica del tracto intestinal humano» (MetaHIT) respectivamente. Además se estableció que los datos generados por el IHMC estarían a disposición en las bases de datos públicas en $\mathrm{EBI}$ y NCBI; y que este consorcio estaría formado no sólo por los investigadores, sino también por las entidades que financian los proyectos [2, 19, 20]. La última reunión del Consorcio Internacional Microbioma Humano, tuvo lugar en septiembre de este año en Hangzhou, China. 
El estudio de nuestro microcosmos: las comunidades microbianas asociadas al cuerpo humano - J. Llanos.

El objetivo de IMHC es trabajar en un marco de principios y resguardos comunes, para estudiar y comprender el rol del microbioma humano tanto en la salud como en la enfermedad y usar este conocimiento para lograr prevenir y tratar enfermedades.

Mayores antecedentes sobre las reuniones internacionales que se han efectuado desde el 2005, de los miembros participantes en el IHMC y de su programa, principios y objetivos, se encuentran en el sitio web http://www.human-microbiome.org/ index.php?id=25.

\section{¿QUÉ HEMOS APRENDIDO GRACIAS A ESTAS DIVERSAS INICIATIVAS?}

\section{La microbiota intestinal separa a los individuos en tres Enterotipos}

Los primeros estudios en relación a la microbiota intestinal, se enfocaron sobre poblaciones particulares tanto en Norteamérica [4], como en Europa [11]. Con el fin de obtener información que permitiera comparar distintas poblaciones, Arumugam et al. [1], analizaron 22 muestras fecales desde individuos provenientes de 4 países europeos (Dinamarca, Francia, Italia y España) y los resultados fueron contrastados con aquellos publicados previamente (muestras desde individuos japoneses 10] y americanos [8, 24], totalizando 33 muestras. El análisis comparativo, señala que las muestras estudiadas se ordenan en tres grupos que fueron denominados Enterotipos, caracterizados por comunidades bacterianas diferentes. Algunos aspectos a destacar en relación a estos grupos son los siguientes:

- Cada enterotipo presenta un predominio de cada una de los siguientes géneros bacterianos: bacteroides (enterotipo 1), Prevotella (enterotipo 2) y Ruminococcus (enterotipo 3)

- El predominio de distintas bacterias en cada grupo, indica que cada enterotipo usa un mecanismo metabólico distinto para producir energía desde los sustratos fermentables disponibles en el colon. La producción de metabolitos secundarios (por ejemplo vitaminas), también se da en proporciones diferentes, siendo los enterotipos 1 y 2 los que sintetizan la mayor variedad de vitaminas (Ej.: biotina, tiamina, riboflavina)

- Las diferencias filogenéticas y funcionales entre los enterotipos, refleja una diferente combinación de las cadenas tróficas, lo cual tiene probablemente un impacto sobre las interrelaciones sinérgicas con el hospedero

- Los enterotipos no dependen de la nacionalidad ni de un continente particular, sino que están principalmente «manejados» por la composición de especies. Sin embargo, la abundancia de funciones no está necesariamente dada por la abundancia de especies

- Las propiedades individuales de cada hospedero (índice de masa corporal, edad o género), no se asocian con un enterotipo particular, pero hay muchos genes y factores en la microbiota intestinal, que si están directamente relacionados con determinadas características de sus hospederos. Por ejemplo, 20 genes se correlacionan directamente con la edad y tres con el índice de masa corporal [1]

Qin et al. [16], señalan que «para comprender el impacto de los microorganismos intestinales en nuestra salud, es crucial evaluar su potencial genético». Con este fin, los investigadores caracterizaron 3,3 millones de genes microbianos no redundantes, desde muestras fecales de 124 individuos europeos. Este grupo de genes, 150 veces mayor que los complementarios genes humanos, corresponden en su gran mayoría a los genes microbianos más frecuentes. Los genes son ampliamente compartidos entre los individuos de la cohorte y sobre el 99\% corresponden a genes bacterianos. Además, los investigadores definen el «metagenoma intestinal mínimo y el genoma bacteriano-intestinal mínimo, en términos de las funciones presentes en todos los individuos y la mayoría de las bacterias respectivamente».

Bacterias simbiontes con genomas extremadamente pequeños, han sido descritas solo recientemente. Estas poseen un diminuto grupo de genes y carecen de algunos que son considerados esenciales en otras bacterias. Como parte de su genoma mínimo estas bacterias mantienen, además de las funciones esenciales, un gran número de funciones que sirven a su hospedero, lo cual resulta de gran interés para estudiar las relaciones microbiota-hospedero [14]. Acorde con estos nuevos conceptos, el extenso catálogo de genes establecido por Qin et al. [16], abre la puerta a futuros estudios sobre la asociación de los genes microbianos con los fenotipos humanos, considerando su ambiente, estilos de vida, dieta, etc.; lo cual llevará a una mejor compresión de nuestra biología. 
El estudio de nuestro microcosmos: las comunidades microbianas asociadas al cuerpo humano - J. Llanos.

\section{Microbiota vaginal}

Sabido es que las comunidades bacterianas cuyo hábitat es la zona vaginal, juegan un papel fundamental como barrera de defensa frente a organismos patógenos y por lo tanto, operan como protectores de la salud en la mujer. La producción de ácidos (fundamentalmente ácido láctico), como resultado de procesos de fermentación bacteriana, es clave para inhibir el crecimiento de organismos patógenos. Sin embargo, los mecanismos globales mediante los cuales las comunidades bacterianas excluyen a otros organismos, no son bien conocidos. Gajer et al. [5], postulan que para predecir el riesgo de enfermedades que afectan la salud de las mujeres, es importante identificar los factores que afectan la estabilidad de las comunidades bacterianas de la vagina.

Varios grupos de investigación han abordado el estudio de la microbiota vaginal $[5,12,18,21]$. Gajer et al. [5], estudiaron las comunidades bacterianas de 32 mujeres en edad reproductiva y de distinta procedencia étnica, a las cuales se les tomaron semanalmente 2 muestras vaginales, durante un periodo de 16 semanas. Las bacterias presentes en cada muestra fueron identificadas mediante análisis de secuencias de RNAr 16S. Además, se caracterizó la función de las comunidades vaginales mediante la determinación de los metabolitos producidos durante las 16 semanas de muestreo.

Los resultados derivados de este estudio revelan fluctuaciones temporales a nivel individual. Estos cambios en la microbiota vaginal, estuvieron principalmente asociados con la composición de la comunidad bacteriana, el periodo del ciclo menstrual y la actividad sexual. Cabe destacar que en la mayoría de los casos el perfil metabólico se mantiene, a pesar de los cambios en la composición de la comunidad.

Al comparar las distintas mujeres estudiadas, se detecta la presencia de 5 grupos que difieren en la dinámica de sus comunidades bacterianas, algunas de estas comunidades cambian marcadamente en un corto tiempo mientras que otras son relativamente estables.

Predominio de Lactobacillus sp.: en tres de los cinco grupos, las comunidades vaginales estuvieron dominadas por bacterias productoras de ácido láctico. Los grupos LC (5 mujeres), LG (2 mujeres), presen- taron la mayor parte del tiempo (16 semanas), un predominio de L. crispatus y $L$. gasseri respectivamente, mostrando una baja transición desde un tipo de comunidad a otra, lo cual permite definirlas como estables. Las variaciones temporales observadas en estas mujeres estuvieron asociadas al periodo menstrual. El tercer grupo (LI, 13 mujeres), estuvo dominado por $L$. iners, pero a diferencia de los dos anteriores, varía ampliamente en su estabilidad y composición de especies, señalando los autores, que esto puede ser reflejo de la heterogeneidad genómica de la especie dominante [5]. Los otros dos tipos de comunidades corresponden a los grupos DA (3 mujeres), que presenta especies previamente asociadas con vaginosis [12] y DB (9 mujeres), que exhibe una baja diversidad de anaerobios y lactobacilos. Algunas conclusiones que pueden señalarse desde el estudio de la dinámica temporal de la microbiota vaginal son [5]:

- La obtención de una sola muestra puede no ser significativa, cuando se trata de diagnosticar una patología, por ejemplo una vaginosis

- Se debe tener en cuenta las variaciones temporales a la hora de diagnosticar y tratar a mujeres con determinadas patologías

- Dada esta diversidad no puede asumirse que todas las mujeres responderán de igual manera a un mismo tratamiento

El aumento de la riqueza taxonómica y la diversidad de las comunidades microbianas en la vagina, han sido asociadas a vaginosis bacteriana [12, $18,21]$. De acuerdo a esto, las variaciones en la microbiota vaginal pueden aumentar la susceptibilidad a enfermedades y de allí la importancia de conocer cabalmente las causas y consecuencias de estas modificaciones [5]. Una mayor comprensión de la ecología microbiana a nivel vaginal, puede llevar al desarrollo de nuevas estrategias para «mantener» la microbiota en forma tal que promueva la salud y minimice el uso de antibióticos.

\section{Bacterias simbiontes de nuestra piel colaboran con nuestro sistema inmune}

Sabido es que la piel representa la primera línea de defensa de nuestro cuerpo frente a microorganismos patógenos (inmunidad innata), ejerciendo un rol protector mediante diversos mecanismos. Uno de ellos es la producción de péptidos antimicrobianos, moléculas producidas en 
El estudio de nuestro microcosmos: las comunidades microbianas asociadas al cuerpo humano - J. Llanos.

todos los órganos del cuerpo por diversos tipos de células, incluidas las que conforman la epidermis [25].

Las bacterias también producen compuestos, llamados bacteriocinas, cuya finalidad es inhibir el desarrollo de otras bacterias. Staphylococcus epidermidis, bacteria comensal que domina en las comunidades bacterianas que habitan nuestra piel, produce varios tipos de bacteriocinas, la mayoría de ellas codificadas por genes plasmidiales [6].

Recientemente se ha señalado cómo la microbiota cutánea colabora con nuestro sistema inmune [6], no sólo compitiendo por las superficies a colonizar, sino también mediante la producción de variados antimicrobianos que actúan de forma específica contra bacterias patógenas, pero no contra los comensales de la piel.

Cuando se requiere de una terapia antibiótica, por ejemplo frente a un problema de acné, se debe considerar que ésta eliminará también nuestros comensales alterando el equilibrio en las comunidades microbianas de la piel y en consecuencia, aumentando el riesgo de colonización por bacterias indeseables (patógenas y patógenas oportunistas). Existe evidencia que asocia enfermedades como acné, dermatitis atópica, psoriasis y rosácea con un desbalance en la microbiota [6, 22].

Frente a esta problemática y considerando el carácter selectivo de los antimicrobianos de origen bacteriano que sólo «atacan» bacterias patógenas, cabe destacar el potencial que poseen estas moléculas para ser usados como alternativa de reemplazo a los antibióticos, en el caso de infecciones que afectan nuestra piel [6].

Otro aspecto de interés asociado a la alteración de nuestra microbiota cutánea, dice relación con la capacidad de restauración de estas comunidades después de un tratamiento antibiótico o una injuria, pues como ya se ha destacado, nuestra microbiota «normal» es importante para mantener la salud de nuestra piel.

La capacidad de restauración no solo es importante para las bacterias comensales de nuestra piel, sino para todas las comunidades bacterianas cuyo hábitat natural es nuestro cuerpo. Bajo determinadas condiciones, la composición y estructura de una comunidad bacteriana puede cambiar a un estado de transición. Sin embargo, si dicha comunidad es resiliente, esta restaurará su estado «normal» una vez recuperada la homeostasis [5]. Lozupone et al. [13], señalan que «comprender cómo nuestra microbiota llega a una condición estable, podría favorecer el desarrollo de estrategias que incrementen la resiliencia a un estado de «salud». Para quienes deseen profundizar este tema en particular, son recomendables las publicaciones de Lozupone et al. [13] y Reid et al. [17].

\section{Palabras finales}

El estudio de las variadas comunidades microbianas que habitan el cuerpo humano, nuestro microcosmos, es un área de la microbiología en plena expansión que en los últimos años ha acercado dos áreas de la microbiología hasta ahora aparentemente divergentes, la ecología microbiana y la microbiología médica. No cabe duda, que en los próximos años, el cúmulo de conocimientos en torno a este tema continuará incrementándose, aportando valiosa información sobre nuestra propia biología. Sin embargo, el desafío principal está en «trasladar» y aplicar esta información al área clínica, lo cual nos puede llevar por ejemplo, a potenciar nuestro sistema inmune, generar nuevas terapias antimicrobianas y acorde a la microbiota individual, nuevos métodos «personalizados» de nutrición y tratamiento frente a ciertas enfermedades.

\section{REFERENCIAS}

1. Arumugam M., J. Raes, E. Pelletier, D. Le Paslier, T. Yamada,D.R. Mende, G.R. Fernandes, J. Tap, T. Bruls, J.-M. Batto, M. Bertalan, N. Borruel, F. Casellas, L. Fernandez, L. Gautier, T. Hansen, M. Hattori, T. Hayashi, M. Kleerebezem, K. Kurokawa, M. Leclerc, F. Levenez, C. Manichanh, H.B. Nielsen, T. Nielsen, N. Pons, J. Poulain, J.Qin, T. Sicheritz-Ponten, S. Tims, D. Torrents, E. Ugarte, E.G. Zoetendal, J. Wang, F. Guarner, O. Pedersen, W.M. de Vos, S. Brunak, J. Doré, MetaHIT Consortium (additional members), J. Weissenbach, S.D. Ehrlich y P. Bork (2011). Enterotypes of the human gut microbiome. Nature, 473: 174-180.

2. Blaser M.J. (2010). Harnessing the power of the human microbiome. PNAS, 107 (14): 6125-6126.

3. Costello E.K., C.L. Lauber, M. Hamady, N. Fierer, J.I. Gordon y R. Knight R (2009). Bacterial Community Variation in Human Body Habitats Across Space and Time. Science, 326 (5960): 1694-1697. 
4. $\quad$ Eckburg P.B., E.M. Bik, C.N. Bernstein, E. Purdom, L. Dethlefsen, M. Sargent, S.R. Gill, K.E. Nelson y D.A. Relman (2005). Diversity of the Human Intestinal Microbial Flora. Science, 308: 1635-1638.

5. Gajer P. R.M. Brotman, G. Bai, J. Sakamoto, U.M.E. Schütte, X. Zhong, S.S.K. Koenig, L. Fu, Z. Ma, X. Zhou, Z. Abdo, L.J. Forney, yJ. Ravel (2012). Temporal Dynamics of the Human Vaginal Microbiota. Sci Trans/Med, 4: 132ra52.

6. Gallo R.L. y T. Nakatsuji (2011). Microbial Symbiosis with the Innate Immune Defense System of the Skin. J Invest Dermatol, 131 (10): 1974-1980.

7. Gevers D., R. Knight, J.F. Petrosino, K. Huang, A.L. McGuire, B.W. Birren, K.E. Nelson, O. White, B.A. Methe y C. Huttenhower (2012). The Human Microbiome Project: A Community Resource for the Healthy Human Microbiome. PLOSBiology, 10(8): e1001377.

8. Gill S.R., M. Pop, R.T. DeBoy, P.B. Eckburg, P. J. Turnbaugh, B.S. Samuel, J.I. Gordon, D.A. Relman, C.M. Fraser-Liggett y K.E. Nelson (2006). Metagenomic Analysis of the Human Distal Gut Microbiome. Science, 312: 13551359.

9. Jeffery I.B. y P.W. O'Toole (2013). Diet-Microbiota Interactions and Their Implications for healthy Living. Nutrients, 5: 234-252.

10. Kurokawa K., T. Itoh, T. Kuwahara, K. Oshima, H. Toh, A. Toyoda, H. Takami, H. Morita, V.K. Sharma, T.P. Srivastava, T.D. Taylor, H. Noguchi, H. Mori, Y. Ogura, D.S. Ehrlich, K. Itoh, T. Takagi, Y. Sakaki, T. Hayashi y M. Hattori (2007). Comparative Metagenomics Revealed Commonly Enriched Gene Sets in Human Gut Microbiomes. DNA Res, 14 (4): 169-181.

11. Lay C., L. Rigottier, K. Holmstrøm, M. Rajilic, E.E. Vaughan,W.M. de Vos, M.D. Collins, R. Thiel, P. Namsolleck, M. Blaut, y J. Doré (2005). Colonic Microbiota Signatures across Five Northern European Countries. Appl Environ microbiol, 71(7): 4153-4155.

12. Ling Z., J. Kong, F. Liu, H. Zhu, X. Chen, Y. Wang, L. Li, K.E. Nelson, Y. Xia y C. Xiang (2010). Molecular analysis of the diversity of vaginal microbiota associated with bacterial vaginosis. BMC Genomics, 11: 488.

13. Lozupone C.A., J.I. Stombaugh, J.I. Gordon, J.K. Jansson y R. Knight (2012). Diversity, stability and resilience of the human gut microbiota. Nature, 489: 220230.

14. McCutcheonJ.P.y N. A. Moran (2012). Extreme genome reduction in symbiotic bacteria. Nature Reviews, 10: 13-26.
15. Mullard A. (2008). The inside story. Nature, 453: 578-580.

16. Qin J., R. Li, J. Raes, M. Arumugam, K. S. Burgdorf. C. Manichanh, T. Nielsen, N. Pons, F. Levenez, T. Yamada, D.R. Mende, J. Li, J. Xu, S. Li, D. Li, J. Cao, B.Wang, H. Liang, H. Zheng, Y. Xie, J. Tap, P.Lepage, M. Bertalan, J-M. Batto, T. Hansen, D. L. Paslier, A. Linneberg, H.B. Nielsen, E. Pelletier, P. Renault, T. Sicheritz-Ponten, K. Turner, H. Zhu, C. Yu, S. Li, M. Jian, Y. Zhou, Y. Li, X. Zhang, S. Li, N. Qin, H. Yang, J. Wang, S. Brunak, J. Dore, F. Guarner, K. Kristiansen, 0. Pedersen, J. Parkhill, J. Weissenbach, MetaHIT Consortium, P. Bork, S. D. Ehrlich y J. Wang (2010). A human gutmicrobial gene catalogue established by metagenomic sequencing. Nature, 464: 59-65.

17. Reid G., J.A. Younes, H.C. Van der Mei, G.B. Gloor, R. Knight y H.J. Busscher (2011). Microbiota restoration: natural and supplemented recovery of human microbial communities. Nature Reviews, 9: 27-38.

18. The Human Microbiome Project Consortium (2012). Structure, function and diversity of the healthy human microbiome. Nature, 486: 207-214.

19. The Human Microbiome Project Consortium (2012). A framework for human microbiome Research. Nature, 486: 215-221.

20. The NIH HMP Working Group (2009). The NIH Human Microbiome Project. Genome Res., 19: 2317-2323.

21. Thies F.L., W. König y B. König (2007). Rapid characterization of the normal and disturbed vaginal microbiota by application of 16S rRNA gene terminal RFLP fingerprinting. J Med Microbiol, 56 (6): 755-761.

22. Trivedi B., (2012). Microbiome: The surface brigade. Nature, Volume:492: Pages: S60-S61

23. Turnbaugh P.J., R. E. Ley, M. Hamady, C. FraserLiggett, R. Knight y J. I. Gordon (2007). The human microbiome project: exploring the microbial part of ourselves in a changing world. Nature, 449: 804-810.

24. Turnbaugh P.J., M. Hamady, T. Yatsunenko, B.L. Cantarel, A. Duncan, R.E. Ley, M.L. Sogin, W.J. Jones, B.A. Roe, J.P. Affourtit, M. Egholm, B. Henrissat, A.C. Heath, R. Knight y J.I. Gordon (2009). A core gut microbiome in obese and lean twins. Nature, 457: 480-484.

25. Zasloff M. (2002). Antimicrobial peptides of multicellular organisms. Nature, 415: 389-395.

\section{CONFLICTO DE INTERESES}

El autor declara no poseer conflicto de intereses. 